\title{
A DIVERSIDADE DO ESPAÇO RURAL E A INFLUÊNCIA DAS RELAÇÕES DE PRODUÇÃO NA EDUCAÇÃO
}

\section{LA DIVERSIDAD DEL ESPACIO RURAL Y LA INFLUENCIA DE LAS RELACIONES DE PRODUCCIÓN EN LA EDUCACIÓN}

\author{
Abigail Bruna da Cruz \\ Mestranda no Programa de Pós-Graduação em Geografia da Universidade Federal de Alfenas-MG \\ abigail.cruz@sou.unifal-mg.edu.br \\ Sandra de Castro de Azevedo \\ Prof $^{a}$. Dr ${ }^{\mathrm{a}}$. Adjunta no Programa de Pós-Graduação em Geografia da Universidade Federal de Alfenas- \\ sandra.azevedo@unifal-mg.edu.br
}

\section{Resumo}

Este artigo objetiva mostrar como a diversidade dentro da categoria Agricultura Familiar pode impactar a educação nas escolas rurais. Para tanto, realizou-se uma caracterização socioespacial das propriedades rurais do distrito de Barranco Alto, do município de Alfenas em Minas Gerais, que é marcadamente composta pelo modo de produção da agricultura familiar. Foram criados quadros mostrando as principais diferenças entre os sete grupos em análise, buscando combinar as informações coletadas e organizadas nos quadros às teorias que tratam a respeito de questões pertinentes aos temas produção, cultura e relações de poder, para adentrar ao tema específico de ensino. Embora seja consideravelmente restrito o espaço rural estudado, esse espaço apresenta grande diversidade em suas dinâmicas socioespaciais já que cada sujeito desempenha um papel diferente nessa teia e isso reflete diretamente no ensino, que deve ser pensado de forma crítica para lançar luz às contradições existentes na sociedade e vivenciadas pelos alunos.

Palavras-chave: Meio Rural. Produção. Diversidade. Relações sociais. Ensino.

\section{Resumen}

Este artículo tiene como objetivo mostrar cómo la diversidad dentro de la categoría de agricultura familiar puede afectar la educación en las escuelas rurales. Para ello, se llevó a cabo una caracterización socioespacial de predios rurales en el distrito de Barranco Alto, en el municipio de Alfenas en Minas Gerais, la cual está marcadamente compuesta por el método de producción de agricultura familiar. Luego, se elaboraron cuadros que muestran las principales diferencias entre los siete grupos bajo análisis, buscando combinar la información recolectada y organizada en los cuadros con las teorías que abordan temas pertinentes a los temas de producción, cultura y relaciones de poder, para luego ingresar al educación temática específica. Si bien el espacio rural estudiado es considerablemente restringido, este espacio presenta una gran diversidad en su dinámica socioespaciales, ya que cada asignatura juega un papel diferente en esta red y esto se 
refleja directamente en la docencia, que a su vez debe ser pensada críticamente para arrojar luz sobre las contradicciones existentes. en la sociedad y experimentada por los estudiantes.

Palabras claves: Campo. Producción. Diversidade. Relaciones Sociales. Enseñando.

\section{Introdução}

Atualmente, o debate sobre os modos de produção no espaço rural no Brasil se baseia na tríade agronegócio, campesinato e agricultura familiar. Geralmente, o primeiro, bem como trouxe Alves e Vale (2013, p.37) “(...) reproduz uma visão economicista da agricultura e do campo, ou seja, a metamorfose do campo em cidade do agronegócio pelo capital das commodities", tornando-se o centro de poder econômico nas áreas rurais do país, criando assim grandes contrastes entre os modos de produção do segundo e o terceiro pilar dessa tríade.

Embora existam similitudes entre as ideias de campesinato e agricultura familiar no que se refere a unidade familiar e a oposição ao agronegócio, quando se trata de como é dada a forma de acesso à terra e a finalidade para a qual é dada a produção dessas duas categorias, as mesmas trazem pontos de distanciamentos entre si. As principais diferenças entre essas categorias está no grau de oposição que cada qual exerce frente ao agronegócio, neste sentido, cabe ressaltar que o campesinato parte do trabalho familiar e a sua produção tem por base comunitária somados a relação de classe enquanto sujeito político, enquanto isso a agricultura familiar, apesar de ter sua base no trabalho familiar, está inserida de forma aprofundada no sistema capitalista, fato que indica as contradições do processo, pois ao se aprofundar nas relações capitalistas para sobreviver coloca em risco sua sobrevivência, pois se distancia do exercício coletivo e comunitário do trabalho e da produção.

$\mathrm{Na}$ atualidade, o termo campesinato vem como sinônimo aos movimentos sociais agrários, mesmo que com perda daquele caráter tradicional de campesinato e de camponês. Para Camacho (2017, p.191), “O MST significa tanto a luta pela conquista da terra, como a luta pela resistência a reprodução do campesinato enquanto classe". Devido a essa ligação do que poderia ser chamado de campesinato moderno com os movimentos socioterritoriais agrários, a oposição ao agronegócio é mais intensa, sê-loiam considerados como modos de produção e de vida extremos entre si. 
A agricultura familiar, por sua vez, poderia ser considerada "um meio termo entre esses dois extremos", pois, segundo Wanderley (2003, p.44), "A ideia central é a de que o agricultor familiar é um ator social da agricultura moderna e, de uma certa forma, ele resulta da própria atuação do Estado". A autora afirma que mesmo essa identidade tenha sido atribuída pelo Estado, os próprios agricultores a assimilaram, pois, não é um termo pejorativo como outros tantos que já foram utilizados.

Dentro da categoria agricultura familiar há uma grande diversidade de modos de vida, de produção e de posicionamento dos sujeitos que compõem essa categoria frente ao mundo, ao sistema econômico, às relações sociais e às relações próprias de poder que um exerce sobre os outros sujeitos dentro dessa categoria, que ora se aproximam e se confundem ao campesinato, ora se aproximam e se confundem ao agronegócio, mas que pelas suas características não poderiam ser consideradas nem uma nem outra categoria desses dois extremos, por estarem inseridas no modo econômico capitalista e, ao mesmo tempo, por não possuir o poder econômico consolidado para serem considerados como tal.

Tendo em vista as questões levantadas anteriormente, ressalta-se aqui que o objetivo deste artigo não é aprofundar na questão teórica sobre essa tríade, e sim reconhecer a diversidade existente dentro da categoria da agricultura familiar (WANDERLEY, 2003). Já que, por vezes sob o véu das aparências essa diversidade é ocultada, suprimida tanto nos debates acadêmicos quanto no cotidiano escolar (BAGLI, 2006).

Para alcançar o objetivo proposto por este artigo, realizou-se uma caracterização socioespacial das propriedades rurais circundantes do distrito de Barranco Alto, o qual pertence ao município de Alfenas- MG. Tal área é correspondente à parte delimitada pelo quadro em branco na figura (1). Embora a imagem da figura 1 seja do ano de 2020 e a pesquisa tenha sido realizada nos anos de 2015-2016, isso não causa prejuízos à pesquisa, pois as culturas agrícolas mais expressivas do espaço estudado, são as culturas permanentes (café, banana e eucalipto). As mudanças que podem ter ocorrido desde então são em áreas onde há o plantio das culturas temporárias (soja, café, feijão e milho).

Para tanto, foi realizado trabalho de campo no período de 2015 a 2016, tendo sido consideravelmente extenso o período de observação realizada sobre as dinâmicas sociais e espaciais ocorridas neste espaço, pois essa prática era parte dos objetivos propostos para realização da monografia defendida no ano de 2016. Juntamente a essa 
observação, foram realizadas 25 entrevistas com moradores deste espaço, entre eles estavam pessoas adultas e jovens que exerciam as mais diversas funções no meio rural em questão. Cabe ressaltar que para o desenvolvimento deste artigo não foram repassados dados específicos das pessoas do espaço rural estudado, apenas informações gerais e que não torna possível o reconhecimento das mesmas no texto escrito.

Figura 1- Delimitação do recorte territorial do espaço rural estudado.

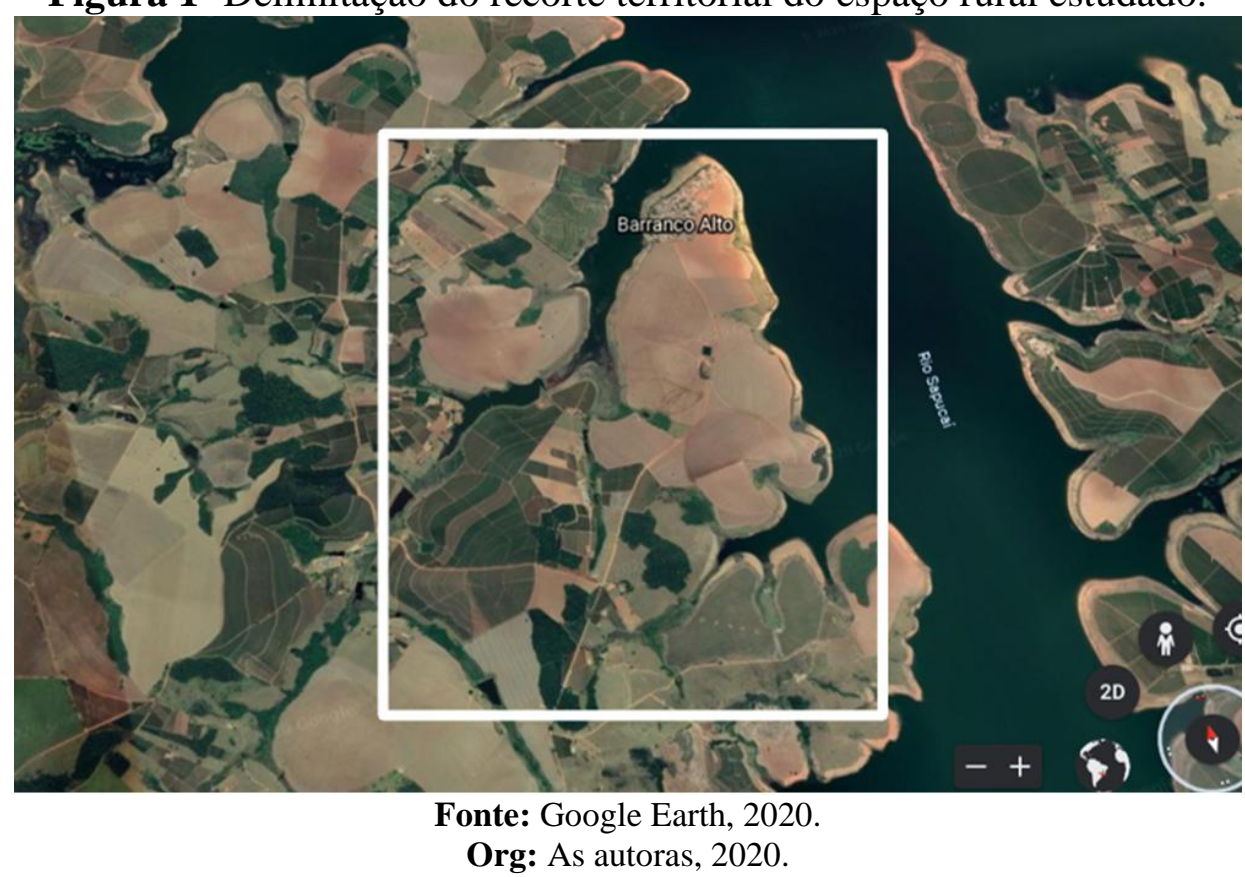

Embora esta pesquisa aconteça em um recorte territorial restrito dentro do município de Alfenas, esse se torna relevante para estudo, pois, os fenômenos que ocorre nesse território não são fenômenos incomuns à escala local e que, de uma forma ou outra, interagem nas demais escalas de análises geográficas, como a escala regional e a global. Do mesmo modo, concorda-se com Lefebvre (2000, p.77) quando este afirma que "o resultado é que o local (o "pontual", determinado por tal ou tal "ponto") não desaparece, absorvido pelo regional, pelo nacional, pelo próprio mundial".

Sobre o município de Alfenas, Alves e Lindner (2020) trouxeram que esse tem uma vasta área direcionada para produção cafeeira, desde a agricultura familiar até àquelas áreas dominadas pelo agronegócio. Portanto, foi realizada uma categorização, com a finalidade de comparar os tamanhos de propriedades, diferenciar os tipos de produção, comparar os modos de produção e reprodução do espaço social, cultural e de 
trabalho, e também como são dadas às relações de poder entre os diversos grupos que compõem o rural em análise.

Depois da caracterização socioespacial, foram criados quadros mostrando as principais diferenças entre os sete grupos analisados, buscando combinar as informações coletadas às teorias que abordam questões pertinentes ao tema produção, cultura e relações de poder, para depois adentrar ao tema específico da educação. Para finalização deste artigo, analisou-se como as relações sociais, econômicas e culturais do espaço onde está localizada a escola influenciam na dinâmica escolar e, consequentemente, na vida dos alunos.

A necessidade das reflexões propostas aqui está pautada na crença de que a escola, que é um dos poucos espaços públicos do rural, é um espaço que pode interferir na autoestima dos alunos, no reconhecimento das contradições existentes na sociedade, possibilitando o desenvolvimento de um pensamento crítico que contribua para a formação de uma consciência crítica sobre o papel desempenhado por cada sujeito no espaço geográfico.

\section{O espaço geográfico rural em estudo: as relações de classes quanto à apropriação da terra}

Pela necessidade de entender as especificidades presentes no campo onde é realizado este estudo, foram construídos sete (7) quadros que trazem observações e características específicas deste rural que muitas vezes não são percebidas no cotidiano, mas que determinam aspectos sociais, culturais e econômicos relevantes para a produção deste espaço. Os quadros apresentados no decorrer dessa pesquisa foram criados com dados primários, buscando pontuar alguns aspectos relevantes para a relação trabalho/campo, que serão relacionados com o ensino/tecnologia. Cada quadro traz informação de uma categoria de Produtor Rural (PR).

No espaço rural estudado, os Produtores Rurais (PRs) que representam a Pequena Propriedade e a Pequena Produção foram retratados nos quadros 1, 2 e 3, respectivamente. São eles; PR-1 Agricultura de subsistência, PR-2 Agricultura familiar em consolidação, com baixo acesso aos meios técnicos científicos informacionais e os PR-3 Agricultura familiar em consolidação, com acesso moderado aos meios técnicos científicos informacionais. Enquanto isso, os Produtores Rurais (PRs) que representam 
a Pequena Propriedade e a Média Produção e a Média Propriedade e a Média Produção foram retratadas nos quadros 4 e 5, respectivamente, e são eles; PR-4 Agricultura familiar consolidada-Arrendatários e os PR-5 Agricultura familiar consolidadaProprietários. Por fim, os Produtores Rurais (PRs) que representam a Grande Propriedade e a Grande Produção foram retratados nos quadros 6 e 7, sendo estes os; PR-6 Agricultura familiar mista/patronal, aos quais os proprietários residem na fazenda e os PR-7 Agricultura familiar mista/ patronal, aos quais os proprietários residem fora do espaço em estudo.

Os dados apresentados nos quadros buscaram considerar o aumento do grau de complexidade existente nas relações do homem com a terra, também nas relações de trabalho existentes entre produtores bem como a relação ao acesso a créditos bancários e aos novos implementos agrícolas disponíveis no mercado. Para essas divisões entre os diversos produtores rurais, teve-se por base legal a Lei $\mathrm{N}^{\circ} 8.629$, de 25 de fevereiro de 1993, da Reforma Agrária. Buscou concentrar a análise dessa pesquisa nas relações de trabalho, propriedade e de produção existentes no espaço rural do distrito do Barranco Alto, buscando analisar como esses elementos impactam no modo de vida da população.

Quadro 1 - Categoria Produtor Rural-1 (Propriedade Pequena/ Pequena Produção).

\begin{tabular}{|l|l|}
\hline \multicolumn{2}{|l|}{ (PR-1) Agricultura de subsistência. } \\
\hline Extensão territorial & Menos de 2 hectares \\
\hline Tipo de produção & Produção familiar \\
\hline $\begin{array}{l}\text { Atividades } \\
\text { desenvolvidas }\end{array}$ & $\begin{array}{l}\text { Pequenas hortas, produção de arroz, milho, feijão e criação de } \\
\text { animais, como: galinhas, porcos e vacas (necessidades básicas) }\end{array}$ \\
\hline $\begin{array}{l}\text { Realização das } \\
\text { atividades }\end{array}$ & $\begin{array}{l}\text { Trabalho manual, com técnicas rudimentares de manejo da terra e } \\
\text { de criação de animais. }\end{array}$ \\
\hline Quem realiza & $\begin{array}{l}\text { Geralmente são pessoas aposentadas e alguns deles sem núcleo } \\
\text { familiar constituído ou são solteiros. }\end{array}$ \\
\hline $\begin{array}{l}\text { Renda/ Complemento } \\
\text { Da Renda }\end{array}$ & $\begin{array}{l}\text { Sem renda fixa. } \\
\text { Maioria das vezes realizam trabalhos informais nos sítios e nas } \\
\text { fazendas da região. } \\
\text { Baixa especialização ou nenhuma. }\end{array}$ \\
\hline $\begin{array}{l}\text { Integração com o } \\
\text { mercado/destino da } \\
\text { mercadoria }\end{array}$ & $\begin{array}{l}\text { Daquilo que é produzido em suas terras, o que é vendido são } \\
\text { apenas os excedentes para parentes ou vizinhos, não configurando } \\
\text { uma integração com o mercado de forma representativa. }\end{array}$ \\
\hline Relação com a cidade & Realizar compras e atendimento de saúde. (Alterosa e Alfenas) \\
\hline Tamanho da família & De média a grande (composta por 5 a mais membros) \\
\hline Origem & $\begin{array}{l}\text { Do próprio distrito de Barranco Alto, da zona rural do Barranco } \\
\text { Alto, do município de Campo do Meio e do Carmo do Rio Claro. }\end{array}$ \\
\hline
\end{tabular}

Fonte: (Trabalho de Campo, 2016).

Org: As autoras (2020). 
No quadro (1) notou-se um meio rural com características mais tradicionais, devido aos modos de vida que levam esses sujeitos do campo. O intitulado "PR-1" sobrevive somente da renda de trabalhos realizados nas fazendas e nos sítios que o cerca. Quando esses sujeitos não podem mais oferecer seu trabalho manual e ainda não estão aposentados, veem-se obrigados a venderem suas terras e partirem para as cidades mais próximas.

A população que compõe essa categoria é a maior responsável pela manutenção da cultura e da tradição, que nos dias de hoje já não é vista tão comumente, pois resguardam os saberes e buscam na medida do possível partilhá-los com as gerações mais novas, um exemplo dessa cultura que tenta resistir na atualidade é a cultura das medicinas naturais, através das práticas alimentares e da cultura dos benzimentos.

Cabe ressaltar que quanto mais antiga é a população deste campo, maior é a sua relação de fé e menor é a inserção de tecnologias em seu cotidiano, em seus afazeres. No espaço estudado, a maioria das famílias são da religião católica e buscam, sobretudo entre os idosos, manter suas tradições através das manifestações culturais, como a chamada Folia de Reis, os terços na comunidade e também a Barqueata, que é realizada todos os anos por seus moradores.

Figura 2- Manifestações culturais em Barranco Alto, Folia de Reis e a Barqueata.
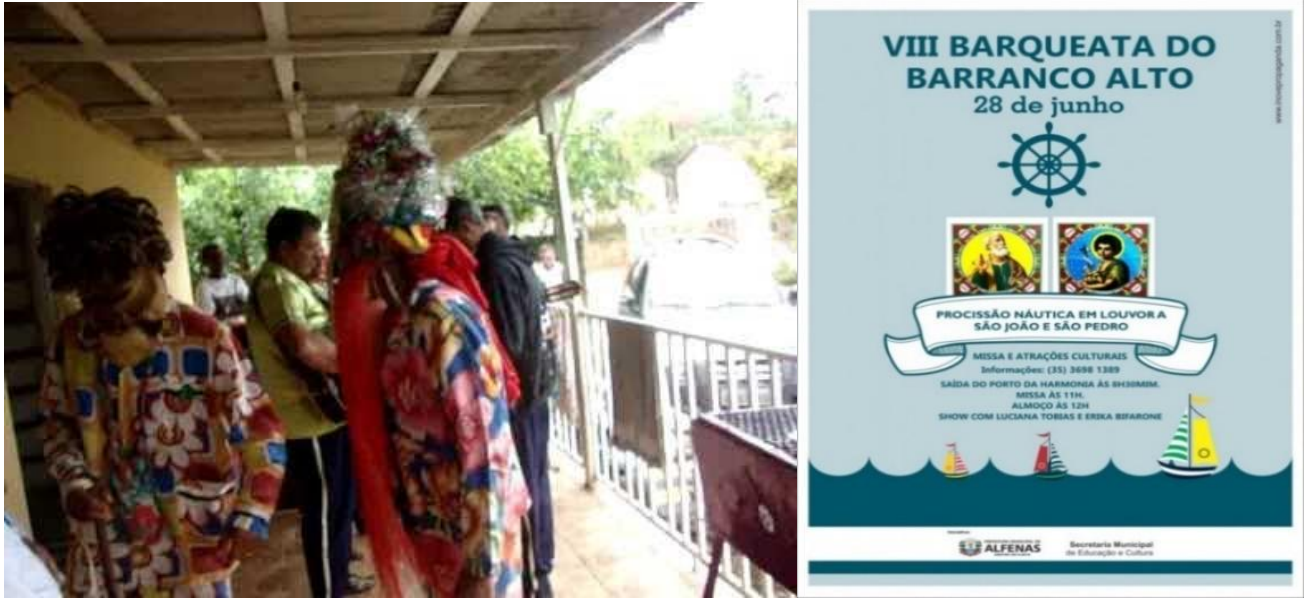

Fonte: Site Alfenas Agora, 2020.

As crianças e adolescentes residentes nesse meio buscam lazer nos fins de semana ou após realizações das atividades que a eles são destinadas, como estudar, ou a realização de trabalhos junto aos pais ou mesmos os trabalhos nas fazendas. Entre as atividades procuradas por esses jovens, estão: os jogos de futebol no campo de chão 
batido, visitas e conversas com os vizinhos, e sobretudo, a visita às igrejas, bares e outros atrativos que se têm nas cidades mais próximas. Esse fato levanta uma questão pertinente a âmbito da política municipal, pois não há espaço público destinado ao lazer nessa área rural.

Quadro 2 - Categoria Produtor Rural-2 (Propriedade Pequena/ Pequena Produção).

\begin{tabular}{|l|l|}
\hline \multicolumn{2}{|c|}{ (PR-2) Agricultura familiar não consolidada. } \\
\hline Extensão territorial & De 2 hectares a 4. \\
\hline Tipo de produção & Produção familiar \\
\hline Atividades desenvolvidas & $\begin{array}{l}\text { Pequenas hortas, produção de arroz, milho, feijão e criação de } \\
\text { animais, como: galinhas, porcos e vacas (Necessidades } \\
\text { básicas). }\end{array}$ \\
\hline Realização das atividades & $\begin{array}{l}\text { Trabalho manual e indícios de técnicas de manejo da terra e de } \\
\text { criação de animais de formas mais modernas. }\end{array}$ \\
\hline Quem realiza & $\begin{array}{l}\text { Homens, mulheres e adolescentes, geralmente membros da } \\
\text { mesma família. }\end{array}$ \\
\hline $\begin{array}{l}\text { Renda/ Complemento Da } \\
\text { Renda }\end{array}$ & $\begin{array}{l}\text { Sem renda fixa. } \\
\text { Maioria das vezes realizam trabalhos informais nas fazendas } \\
\text { da região. (Por dia ou empreitas) } \\
\text { Trocam dias de serviços com outros "PR-2" e "PR-3". } \\
\text { Parte deles vendem os excedentes da sua produção. } \\
\text { Apresentam baixa especialização. } \\
\text { Utilizam algum tipo de crédito oferecido pelo governo. (Ex: } \\
\text { Pronaf) }\end{array}$ \\
\hline $\begin{array}{l}\text { Integração com o mercado/ } \\
\text { destino da mercadoria }\end{array}$ & $\begin{array}{l}\text { A integração dessa categoria com o mercado, de forma geral, é } \\
\text { baixa, pois vendem apenas os excedentes da sua produção para } \\
\text { o mercado interno e não têm grande poder de compras. }\end{array}$ \\
\hline Relação com a cidade & $\begin{array}{l}\text { Realizar compras e atendimento de saúde. (Alterosa e } \\
\text { Alfenas). Lazer entre jovens. }\end{array}$ \\
\hline Tamanho da família & Pequena (composto por poucos membros) \\
\hline Origem & $\begin{array}{l}\text { Do próprio distrito de Barranco Alto, da zona rural do } \\
\text { Barranco Alto, do município de Campo do Meio e do Carmo } \\
\text { do Rio Claro. }\end{array}$ \\
\hline
\end{tabular}

Fonte: (Trabalho de Campo, 2016).

Org: As autoras (2020).

No quadro (2) notou-se que os membros da família desenvolvem as atividades em seu próprio sítio, mas têm a necessidade de trabalhar em outros locais, mesmo que na forma de troca de serviços com outros produtores familiares ou como assalariado nas fazendas vizinhas.

Quando é pensado no trabalho familiar, é necessário lembrar que embora as mulheres realizem muitas das suas atividades no meio rural, tanto em suas propriedades quanto nas propriedades vizinhas, não há o devido reconhecimento das mesmas, sejam elas pertencentes a qualquer das categorias aqui representadas. Seu trabalho continua sendo subjugado em relação ao trabalho masculino. Muitas vezes elas não são 
registradas e fazem papel secundário nesta sociedade, ainda fortemente patriarcal e machista. Silva (2010, p.43) explica que "a execução de tarefas no âmbito familiar é vista pelos homens como trabalho feminino apropriado, não-remunerado, obrigação natural feminina, ato de amor para com o esposo e os filhos, sendo pouco valorado na sociedade de mercado".

Outro aspecto que pode ser notado nesta categoria "PR-2" é a necessidade muitas vezes primordial de realizar algum tipo de financiamento para manutenção de sua propriedade, como é o caso do Programa Nacional de Fortalecimento da Agricultura Familiar (PRONAF), onde a terra é depositada como garantia e recebe um valor para manejo e desenvolvimento de alguma atividade no seu sítio, sobre o qual pagará juros. Segundo Schneider (2014, p.34), o PRONAF "trata-se de uma política de crédito para custeio e investimento, que a cada ano é lançada no âmbito do Plano Safra da agricultura familiar, após as negociações entre o governo e os atores sociais". Aqueles que procuram esse apoio buscam o aumento da produção e da renda familiar, mas, sobretudo, esse financiamento vem como incentivo para que se produza na terra, pois, muitas vezes por falta de condições financeiras, o produtor não tem como iniciar ou mesmo fazer o manejo de quaisquer atividades. Entre os financiamentos mais procurados pelos moradores dessa área em estudo, estão os financiamentos para investimento em implementos agrícolas, para custeio de fertilizantes e agrotóxicos para controle de pragas e para pesca artesanal.

É necessário pontuar que esses empréstimos são feitos através de financiamentos bancários, portanto, esses produtores têm que dar garantias que este "apoio" voltará ao financiador, e a garantia dada, muitas vezes, é a própria terra, onde esse produtor nasceu, cresceu, criou sua família e outros tantos vínculos. Entende-se que, se por um lado a realização do financiamento é o que garante a manutenção das atividades nos seus sítios, por outro lado fica a insegurança desse produtor em relação a intempéries climáticas ou outras adversidades que venham a comprometer a produção. Em casos de perda da produção, consequentemente, o reembolso da quantia que foi emprestada não será efetivado. Ao invés de vender seu sítio, haverá a penhora do mesmo pelo banco que gerou o empréstimo e a terra desses produtores são colocadas para serem leiloadas. Surge então uma questão inquietante, que mostra as contradições do capitalismo: para contribuir com a permanência do agricultor familiar no campo, o mesmo financia sua 
produção e ao mesmo tempo que mantém sua terra, que é o meio de sua sobrevivência, à entrega como garantia em caso de não cumprimento do financiamento, e independentemente do motivo, seja este por intempéries climáticas, pragas na lavoura, baixa do preço da produção no mercado, esses perdem suas terras, colocando o agricultor em uma situação de insegurança constante.

Quadro 3 - Categorias Produtor Rural 3 (Propriedade Pequena/Pequena Produção)

\begin{tabular}{|c|c|}
\hline \multicolumn{2}{|c|}{ (PR-3) Agricultura familiar em consolidação } \\
\hline Extensão territorial & De 4 hectares a 8. \\
\hline Tipo de produção & Produção familiar \\
\hline Atividades desenvolvidas & $\begin{array}{l}\text { Especializam em um tipo de produção principal: Banana, café } \\
\text { e gado. } \\
\text { Desenvolvem produção secundária como: Milho, feijão e } \\
\text { hortaliças. }\end{array}$ \\
\hline Realização das atividades & $\begin{array}{l}\text { Baixo índice de trabalho manual e emprego de técnicas de } \\
\text { manejo da terra e de criação de animais de formas mais } \\
\text { modernas. } \\
\text { Uso de colheitadeiras de pequeno porte, roçadeiras e } \\
\text { sopradores e tratores. (Algumas Vezes) }\end{array}$ \\
\hline Quem realiza & $\begin{array}{l}\text { Homens, mulheres e adolescentes, geralmente membros da } \\
\text { mesma família. }\end{array}$ \\
\hline $\begin{array}{l}\text { Renda/ Complemento da } \\
\text { Renda }\end{array}$ & $\begin{array}{l}\text { Sem renda fixa. } \\
\text { Maioria das vezes realizam trabalhos informais nas fazendas } \\
\text { da região. (Por dia ou empreitas) } \\
\text { Trocam dias de serviços. } \\
\text { Parte deles vendem os excedentes da sua produção. } \\
\text { Alguns com especialização. } \\
\text { Utilizam algum tipo de crédito oferecido pelo governo. (Ex.: } \\
\text { Pronaf) }\end{array}$ \\
\hline $\begin{array}{l}\text { Integração com o mercado/ } \\
\text { destino da mercadoria }\end{array}$ & $\begin{array}{l}\text { Parcial. Esses produtores vendem seus excedentes, porém não } \\
\text { negociam diretamente com os compradores, precisando de } \\
\text { atravessadores para desempenhar este papel. A partir dessa } \\
\text { categoria, o poder de compra desses produtores se torna um } \\
\text { pouco mais expressivos. }\end{array}$ \\
\hline Relação com a cidade & $\begin{array}{l}\text { Realizar compras e atendimento de saúde. (Alterosa e } \\
\text { Alfenas). Lazer entre jovens. }\end{array}$ \\
\hline Tamanho da família & Pequena (composto por poucos membros) \\
\hline Origem & $\begin{array}{l}\text { Do próprio distrito de Barranco Alto, da zona rural do } \\
\text { Barranco Alto, do município de Campo do Meio e do Carmo } \\
\text { do Rio Claro. }\end{array}$ \\
\hline
\end{tabular}

Fonte: (Trabalho de Campo, 2016).

Org: As autoras (2020).

Os PR-1, PR-2 e PR-3 são oriundos dos espaços rurais do entorno do distrito de Barranco Alto, ou do próprio distrito em si, do município do Carmo do Rio Claro e do município de Campo do Meio. 
Nessa categoria, caracterizada no quadro (3), é comum a venda da sua força de trabalho pago por dia e também a realização de trabalhos feitos por "empreitas", sendo realizados na forma de serviços eventuais, sem a contratação ou realização de registros em carteira profissional. Ficando a cargo do dono da terra e dos trabalhadores a negociação do valor a ser recebido pelo trabalho oferecido, que nem sempre condiz com o esforço físico empregado na labuta. Muitos destes trabalhadores não têm seus direitos garantidos por lei, devido à informalidade da realização destes trabalhos, que embora sejam práticas consideradas recorrentes, não são fixas. Percebe-se que nesse campo não possui líderes que reclamem sobre essas questões, e talvez, pela própria desinformação, são levados a aceitar as condições a que são submetidos sem questionar.

Assim como o produtor "PR-2", o produtor "PR-3" resiste na terra, também se submete aos processos de inserção tecnológica para aumento da produção e de diminuição do uso de trocas de serviço. Ao mesmo tempo que essa categoria está se especializando mais que a categoria anterior, ainda sofre com a insegurança causada pelas incertezas que geram os financiamentos.

A categoria PR-1 são aqueles cujas famílias são maiores, com média de 6 a 8 membros por cada núcleo familiar, mas, cabe ressaltar que, com passar do tempo, essas pessoas (filhos e filhas) saem das casas dos seus pais e formam suas próprias famílias. As categorias PR-2 e PR-3 são compostas por pessoas mais novas e a quantidade de membros por famílias são menores, numa média de 4 a 5 pessoas por núcleo familiar.

Em relação a integração dessas 3 categorias com o mercado, é uma integração parcialmente baixa. No caso específico dos PR-1, essa integração é pouco representativa. Cabe ressaltar que embora haja o acesso ao mercado, muitos precisam trabalhar com atravessadores, sendo assim, não são os próprios moradores/produtores que estabelecem relações/diálogos diretos com o mercado.

Outro aspecto averiguado é que essas três categorias mantêm relações com as cidades de Alterosa e de Alfenas, na maioria das vezes para realização de compras mensais de alimentos e para atendimento médico (exames e acompanhamento de rotina). Já os jovens que compõem essas categorias vão para essas cidades para realizar algum tipo de lazer e socialização, porém em baixa frequência, pois isso demanda certo custo e veículos para realização da mobilidade. 
Quadro 4 - Produtor Rural 4 (Propriedade Pequena/Média Produção). (PR-4) Agricultura familiar consolidada (Arrendatários)

\begin{tabular}{|c|c|}
\hline Extensão territorial & De 8 hectares a 15. \\
\hline Tipo de produção & Produção familiar. \\
\hline Atividades desenvolvidas & $\begin{array}{l}\text { Um tipo de produção principal: Banana, café ou gado. } \\
\text { Desenvolvem produção secundária como a produção de milho } \\
\text { e feijão. }\end{array}$ \\
\hline Realização das atividades & $\begin{array}{l}\text { Baixo índices de trabalho manual e emprego de técnicas de } \\
\text { manejo da terra. } \\
\text { Uso de tratores e instrumentos para beneficiamento da } \\
\text { produção. } \\
\text { Algumas vezes são empregadores. (Época de safra alta) }\end{array}$ \\
\hline Quem realiza & $\begin{array}{l}\text { Na maioria das vezes são atividades realizadas somente pelos } \\
\text { homens. }\end{array}$ \\
\hline $\begin{array}{l}\text { Renda/ Complemento Da } \\
\text { Renda }\end{array}$ & $\begin{array}{l}\text { Oferta de trabalho nos sítios menores. } \\
\text { Exemplo: uma hora de serviço de trator vale } \mathrm{R} \$ 70,00 \text { (setenta } \\
\text { reais), ou seja, mais que o dia de um assalariado. (2016). }\end{array}$ \\
\hline $\begin{array}{l}\text { Integração com o mercado/ } \\
\text { destino da mercadoria }\end{array}$ & $\begin{array}{l}\text { Integração parcial com o mercado interno. Associam-se às } \\
\text { cooperativas e trabalham com atravessadores. Têm um poder } \\
\text { de compra razoável em relação aos PRs anteriores. }\end{array}$ \\
\hline Relação com a cidade & $\begin{array}{l}\text { Realizam compras e atendimento de saúde, lazer (Alterosa e } \\
\text { Alfenas) e às vezes possuem casas na cidade, mas } \\
\text { permanecem morando na roça. (Alterosa) }\end{array}$ \\
\hline Tamanho da família & Pequena (composto por poucos membros) \\
\hline Origem & $\begin{array}{l}\text { Do próprio distrito de Barranco Alto, da zona rural do } \\
\text { Barranco Alto, do município de Campo do Meio e do Carmo } \\
\text { do Rio Claro. }\end{array}$ \\
\hline
\end{tabular}

Os produtores PR-4 e PR-5, representados nos quadros (4 e 5), são mais independentes de trocas de serviços e, para complemento de renda, oferecem serviços com implementos agrícolas de seu próprio uso. Como dito no quadro anterior, a oferta de uma hora de trabalho com um trator é equivalente a $\mathrm{R} \$ 70,00$ (setenta reais), sendo que o referente a um dia de trabalho de um assalariado gira em torno de $\mathrm{R} \$ 32,00$ (trinta e dois reais), esses valores são referentes ao ano de 2016, havendo relação de exploração até mesmo entre as classes sociais menos abastadas. Mas, devido às necessidades, muitas vezes de ordem imediatistas, fazem com que esse fenômeno se torne natural, como se fosse uma "exploração necessária” e muitas vezes mútua. 
Quadro 5 - Produtor Rural 5 (Propriedade Média/Média Produção). (PR-5) Agricultura familiar consolidada (Proprietários da terra)

\begin{tabular}{|c|c|}
\hline Extensão territorial & De 15 hectares a 25. \\
\hline Tipo de produção & Produção familiar. \\
\hline Atividades desenvolvidas & $\begin{array}{l}\text { Um tipo de produção principal: Banana, café ou gado. } \\
\text { Desenvolvem produção secundária como a produção de milho } \\
\text { e feijão. }\end{array}$ \\
\hline Realização das atividades & $\begin{array}{l}\text { Baixo índices de trabalho manual e emprego de técnicas de } \\
\text { manejo da terra. } \\
\text { Uso de tratores e instrumentos para beneficiamento da } \\
\text { produção. } \\
\text { Algumas vezes são empregadores. (Época de safra alta) }\end{array}$ \\
\hline Quem realiza & $\begin{array}{l}\text { Na maioria das vezes são atividades realizadas somente pelos } \\
\text { homens e as vezes contratam pessoas de fora temporariamente } \\
\text { em época de safra alta }\end{array}$ \\
\hline $\begin{array}{l}\text { Renda/ Complemento da } \\
\text { Renda }\end{array}$ & $\begin{array}{l}\text { Baixa oferta de trabalho nos sítios menores. } \\
\text { Exemplo: uma hora de serviço de trator vale } \mathrm{R} \$ 70,00 \text { (setenta } \\
\text { reais), ou seja, mais que o dia de um assalariado. (2016). }\end{array}$ \\
\hline $\begin{array}{l}\text { Integração com o mercado/ } \\
\text { destino da mercadoria }\end{array}$ & $\begin{array}{l}\text { A integração desses produtores ao mercado é parcial elevada, } \\
\text { já possuem um poder de compra maior e menor dependência } \\
\text { de atravessadores para a realização de suas vendas. Atuam no } \\
\text { mercado interno com culturas temporárias, além da pecuária e } \\
\text { exportação (sobretudo do café). }\end{array}$ \\
\hline Relação com a cidade & $\begin{array}{l}\text { Realizar compras e atendimento de saúde, lazer (Alterosa e } \\
\text { Alfenas) e às vezes possui casas na cidade, mas continuam } \\
\text { morando na roça. (Alterosa) }\end{array}$ \\
\hline Tamanho da família & Pequena (composto por poucos membros) \\
\hline Origem & $\begin{array}{l}\text { Do próprio distrito de Barranco Alto, da zona rural do } \\
\text { Barranco Alto, do município de Campo do Meio e do Carmo } \\
\text { do Rio Claro. }\end{array}$ \\
\hline
\end{tabular}

Org: As autoras (2020).

Nessas categorias de produtores, é extremamente forte a inserção de eletrodomésticos, eletroeletrônicos e outros recursos que, a princípio, são associados aos modos de vida urbano. Esse fenômeno, segundo Carneiro (1988, p.58), mostra que essa localidade rural está sendo submetida a uma "reestruturação a partir da incorporação de novos componentes econômicos, culturais e sociais (...) percebidas através da interação entre os atores sociais e os sistemas culturais aos quais eles são referidos". Com isso, muitos assimilam em sua rotina costumes parecidos com os costumes urbanos, mas não se pode tomar esse fenômeno como uma totalidade, já que essas inserções acontecem em intensidades diferentes e em tempos diferentes para cada grupo e/ou indivíduos.

Outro fator observado a partir da inserção dessas tecnologias foi o encurtamento da infância, onde crianças buscam reproduzir modelos e personagens midiáticos. Isso 
foi observado nos modos de vestir, falar, ou mesmo ao considerar a facilidade em se ter acesso aos conteúdos adultos via internet ou televisores. Muitas vezes, conscientes ou não, os pais se submetem a esse processo e se tornam receptores das novas necessidades criadas pela sociedade capitalista, que fazem do modelo urbano o padrão de vida para as demais sociedades, homogeneizando assim a cultura. Essa sensação de coesão espacial e temporal tornam tênues aos olhos as desigualdades ainda existentes e latentes entre as classes sociais. Para exemplificar essa questão, pode ser citado um relato de um adolescente que trabalhou na safra do café fora do horário convencional que é das $07 \mathrm{~h}$ às $16 \mathrm{~h}$, chegando a ficar até às $22 \mathrm{~h}$ sem ganhar o salário extra equivalente ao horário trabalhado. Esse mesmo adolescente comprou um aparelho celular (Iphone6), o qual equivalia, na época, a quase três meses de seu salário, isso no ano de 2016, parcelando o valor do aparelho em diversas prestações, comprometendo seu salário líquido mensal para realização de tal compra.

Muitas vezes o poder de compra torna o trabalhador resignado, ludibriado, pois, embora o poder de compra lhes permita o acesso às mercadorias também usufruídas pelos patrões, o tal acesso é dado com maior sacrifício, enquanto para os empregadores, tendo em vista a relação de mais-valia, a mesma mercadoria é obtida de uma forma corriqueira, não se tornando um processo danoso para a renda no final do mês. Essa alienação associada ao fetichismo que o capital provoca pela mercadoria e pelo modo de vida urbano, faz com que muitos dos habitantes desta área não pensem o mundo a partir do lugar onde vivem, não saibam qual é seu papel como sujeito formador e transformador do espaço e não se reconhecem como sendo sujeitos de direito, pois não têm a consciência de que faz parte dos mecanismos capitalistas.

Bem como os PR-1 e PR-2, PR-3, PR-4 e PR-5 são oriundos dos espaços rurais do entorno do distrito de Barranco, do próprio distrito de Barranco Alto, do município do Carmo do Rio Claro e do município de Campo do Meio. Essa diversidade deve-se ao fato de que, antes das águas de Furna chegarem no ano de 1963, havia um trânsito direto entre os moradores desses municípios, pela sua proximidade geográfica, como pode ser visto nos destaques do mapa 1, acrescido também do município de Alterosa. Martins (2010) explica que Furnas foi a primeira grande usina hidrelétrica do Brasil, estando situada no Sudoeste de Minas Gerais. 
Mapa 1- Proximidade do distrito de Barranco Alto aos municípios vizinhos.

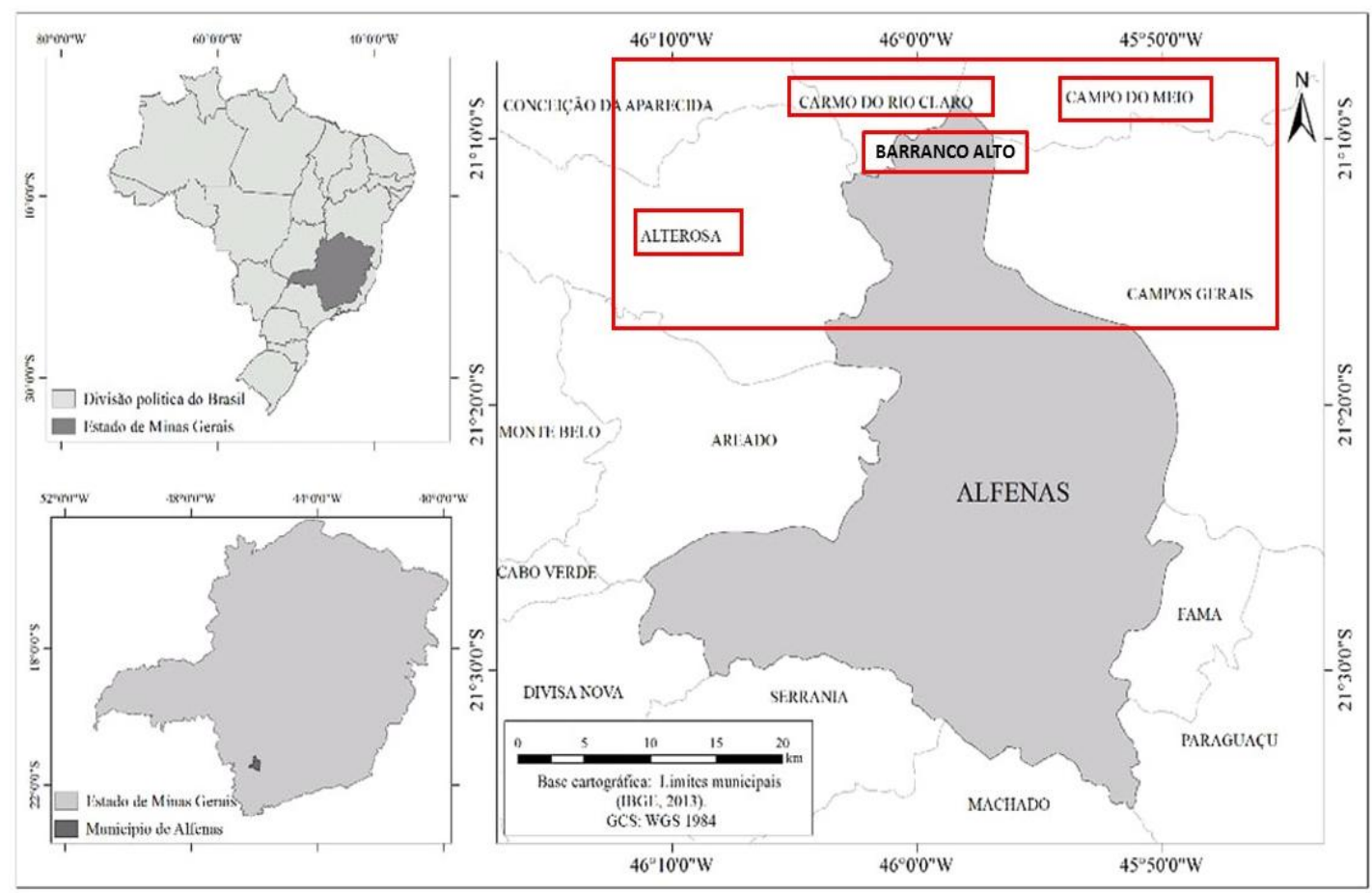

Fonte: Diogo Olivetti et al, 2013.

Adaptado: Pelas autoras, 2021.

Outro fator relevante a ser exposto é que a composição familiar das categorias PR-4 e PR-5 são de poucos membros, variando entre 4 e 5 membros por núcleo familiar, havendo algumas exceções.

Quanto a integração dessas duas categorias com o mercado, há ainda o sistema de atravessamento comercial, como visto nas categorias anteriores, porém já se torna mais comum a associação com Cooperativas, sobretudo com a Cooperativa Regional de Cafeicultores em Guaxupé Ltda. (Cooxupé) que atualmente possui mais de 12000 cooperados, sendo a mais popular nesse espaço estudado.

Sobre as relações dessas categorias (PR-4 e PR-5) com a cidade, tem um pouco mais de proximidade do que as outras três categorias analisadas anteriormente e, além de realizar compras e ir por motivos de saúde e lazer (Alterosa e Alfenas), parte da população dessas categorias possuem casas na cidade, sobretudo em Alterosa, mas continuam morando na roça para exercer seu trabalho, indo apenas de vez em quando ou alugando esses imóveis como renda extra. 
Quadro 6 - Categorias Produtores Rurais 6 (Propriedade Grande/ Grande Produção)

\begin{tabular}{|c|c|}
\hline \multicolumn{2}{|c|}{ (PR-6) Agricultura familiar mista/ patronal. } \\
\hline Extensão territorial & De 25 hectares a 100. \\
\hline Tipo de produção & Produção familiar mista patronal. \\
\hline Atividades desenvolvidas & Agronegócio (Atividades agrosilvopastoris) \\
\hline Realização das atividades & $\begin{array}{l}\text { Intensa mecanização: Possuem colheitadeiras, tratores } \\
\text { modernos, sistema de irrigação. } \\
\text { Contratam serviços de pulverização aérea. }\end{array}$ \\
\hline Quem realiza & $\begin{array}{l}\text { Empregados que realizam serviços especializados. } \\
\text { (Há sobrecarga de trabalho em época de safra/ não é guardado } \\
\text { os feriados). } \\
\text { Alguns são moradores na fazenda em sistema de colonato } \\
\text { (casas antigas, pequenas, faltando estrutura). } \\
\text { Outros vêm das regiões próximas da fazenda com seus } \\
\text { próprios veículos. }\end{array}$ \\
\hline $\begin{array}{l}\text { Renda/ Complemento da } \\
\text { Renda }\end{array}$ & $\begin{array}{l}\text { Além de proprietários da fazenda são veterinários/ médicos/ } \\
\text { professores/ coordenadores pedagógicos entre outros. }\end{array}$ \\
\hline $\begin{array}{l}\text { Integração com o mercado/ } \\
\text { destino da mercadoria }\end{array}$ & $\begin{array}{l}\text { A integração dessa categoria com o mercado é total, não tendo } \\
\text { dependência nenhuma com atravessadores para exercer suas } \\
\text { vendas. Tem alto poder de compra se comparado aos demais } \\
\text { produtores do espaço estudado. Atuam no mercado interno e } \\
\text { alcançam o mercado externo. }\end{array}$ \\
\hline Relação com a cidade & $\begin{array}{l}\text { Possuem casas na cidade para filhos e filhas } \\
\text { (estudos/moradia). Os pais permanecem nas fazendas }\end{array}$ \\
\hline Tamanho da família & Pequena (composto por poucos membros) \\
\hline Origem & $\begin{array}{l}\text { Do próprio distrito de Barranco Alto, da zona rural do } \\
\text { Barranco Alto, do município de Campo do Meio e do Carmo } \\
\text { do Rio Claro. }\end{array}$ \\
\hline & $\begin{array}{l}\text { Fonte: (Trabalho de Campo, 2016). } \\
\text { Org: As autoras (2020). }\end{array}$ \\
\hline
\end{tabular}

Esses grandes produtores, caracterizados nos quadros (6 e 7), mecanizaram sua produção há menos de 20 anos, suas fazendas já não contratam tantos trabalhadores quanto antes, caindo para mais de $70 \%$ desta quantidade. A maioria dos trabalhadores dessas fazendas são especializados em manusear os implementos que essas fazendas possuem. Quanto maior a especialização, maior é o nível de mecanização que os mesmos manuseiam, quanto menor é a especialização, maior a força bruta que os trabalhadores têm que dispor para realização da atividade em desenvolvimento.

Quanto a origem dessas categorias, PR-6 e PR-7 são diferentes entre si. Os PR-6 também são oriundos dos municípios vizinhos ou até mesmo dos arredores rurais do distrito, já os PR-7 geralmente são de Passos, Conceição Aparecida e Andradas. Ambas as categorias têm famílias pequenas, numa média de 3 a 4 membros por núcleo familiar. Essas categorias têm uma alta integração com o mercado, são os maiores representantes do agronegócio no espaço estudado. 
Quadro 7- Categorias Produtores Rurais 7 (Propriedade Grande/ Grande Produção)

\begin{tabular}{|l|l|}
\hline \multicolumn{2}{|c|}{ (PR-7) Agricultura familiar mista/patronal } \\
\hline Extensão territorial & De 25 hectares a 100 (ou mais). \\
\hline Tipo de produção & Produção familiar mista patronal. \\
\hline Atividades desenvolvidas & Agronegócio (Atividades agrosilvopastoris) \\
\hline Realização das atividades & $\begin{array}{l}\text { Intensa mecanização: Possuem colheitadeiras, tratores } \\
\text { modernos, sistema de irrigação. } \\
\text { Contratam serviços de pulverização aérea. }\end{array}$ \\
\hline Quem realiza & $\begin{array}{l}\text { Empregados que realizam serviços especializados. } \\
\text { (Há sobrecarga de trabalho em época de safra/ não é guardado } \\
\text { os feriados). } \\
\text { Alguns são moradores na fazenda em sistema de colonato } \\
\text { (casas antigas, pequenas, faltando estrutura). } \\
\text { Outros vêm das regiões próximas da fazenda com seus } \\
\text { próprios veículos. }\end{array}$ \\
\hline $\begin{array}{l}\text { Renda/ Complemento da } \\
\text { Renda }\end{array}$ & $\begin{array}{l}\text { Além de proprietários da fazenda são administradores e } \\
\text { médicos. }\end{array}$ \\
\hline $\begin{array}{l}\text { Integração com o mercado/ } \\
\text { destino da mercadoria }\end{array}$ & $\begin{array}{l}\text { A integração dessa categoria com o mercado é total, não tendo } \\
\text { dependência nenhuma com atravessadores para exercer suas } \\
\text { vendas. Tem alto poder de compra. Atua no mercado interno } \\
\text { e alcança o mercado externo. }\end{array}$ \\
\hline Relação com a cidade & $\begin{array}{l}\text { Moradia e onde estabelecem seus vínculos afetivos, culturais e } \\
\text { comerciais. De forma geral, a relação com o espaço rural é } \\
\text { econômica/comercial. }\end{array}$ \\
\hline Tamanho da família & Pequena (composto por poucos membros) \\
\hline Origem & Fonsos, Andrada, Conceição da Aparecida, Alfenas. \\
\hline & Org: As autoras (2020).
\end{tabular}

Suas relações com as cidades também são diferentes entre si, bem como as suas origens. Os PR-6 têm casas na cidade, geralmente em Alfenas ou Areado, tanto para os filhos e filhas morarem/estudarem quanto para aluguel, porém os pais permanecem nas suas fazendas para desempenhar suas funções, sejam administrativas ou sejam nas instituições aos arredores (como é o caso da escola). Os PR-7 mantêm relações estreitas com as cidades de origens, sendo nas cidades seus espaços de moradia, onde estabelecem seus vínculos afetivos, culturais e comerciais.

Em cada categoria analisada, a apropriação das tecnologias de informação, como os televisores, os celulares com acesso à internet e os computadores, dão-se em intensidades diferentes e, conforme se tem o acesso a elas, cada categoria dá sentidos e tipos de usos diferentes a essas tecnologias.

Os produtores rurais que possui menor acesso à terra e aos meios de produção, os PR-1, PR-2, PR-3, utilizam tais tecnologias de informações, ou parte delas, mais associadas ao entretenimento. Já os PR-4 e PR-5 usam as tecnologias tanto para o 
entretenimento, quanto para garantia de aumento da produção, como máquinas colheitadeiras de pequeno porte, tratores e implementos agrícolas para contribuição com os trabalhos manuais dos sítios. Enquanto isso, aqueles com maior acesso à terra e, consequentemente, maior nível econômico (PR-6 e PR-7), associam as diferentes tecnologias em prol do aumento da produtividade das fazendas, lazer e acesso ao conhecimento em assuntos variados.

Em ambos os tipos de produtores há uma forte hierarquização entre patrões e empregados. No caso dos produtores PR-6, onde patrões moram na sede rural, essa relação é menos explícita, porém, é existente e os usos de referências nas falas dos moradores mostram e reafirmam essa hierarquia (ex.: "senhor", "senhora”, “dona”). Observa-se também que outro fator que mascara essa hierarquização nesse espaço são as relações de apadrinhamento de filhos dos trabalhadores pelos patrões, o que torna essa relação hierárquica menos explícita.

Essa aproximação entre patrão e empregado não ocorre na mesma intensidade quando pensamos nos produtores PR-7, já que o convívio é mais limitado e as relações com os outros e com a terra passam a ser nitidamente mais empresarial/comercial. Neste sentido, Moreira (2015) afirma que existe uma desespacialização do homem com a natureza, com a terra e com o lugar. O espaço, então, é transformado num dado abstrato, onde o homem é alienado do espaço, e, por consequência, é alienado de si mesmo.

Não percebendo de forma crítica as relações de classes que existem no espaço, parte dessa população não se veem como sendo sujeitos essenciais de produção e de reprodução de valores, culturas e de trabalho nessas terras. Isso faz com que não se criem mecanismos para valorização da terra, e a falta de representatividade, de movimentos sociais como afirmado anteriormente neste texto, faz aumentar ainda mais a relação de submissão dos mesmos frente ao sistema e reforçam as desigualdades nas relações de trabalho, não superando as situações de antagonismos dentro da categoria de agricultores familiares.

Ao realizar as análises dos quadros notou-se que a educação formal representa uma possibilidade de ascensão pessoal e profissional, e através da formação há a possibilidade de menor sujeição desses sujeitos as imposições de terceiros sobre seus trabalhos e vida. Contudo, reconhece-se que a educação formadora foi por muito tempo um privilégio exclusivo daqueles que tinham condições de pagar por ela, neste sentido, 
as elites econômicas de um determinado lugar também representavam uma elite intelectual de tal espaço. Com a redemocratização do ensino essa realidade está mudando aos poucos, embora ainda há pontos latentes que ainda precisam ser repensados para uma maior garantia de acesso e permanência dos diversos sujeitos à educação básica, média e também superior no país. Acredita-se que com o acesso a uma educação transformadora poderia existir uma maior mobilização da população do campo para lutar por políticas públicas para este espaço, pensando assim no coletivo.

\section{As relações entre produção e educação no espaço rural estudado}

Entre os diversos tipos de relações analisadas durante o processo de desenvolvimento desta pesquisa, notou-se que das sete categorias de produtores rurais dessa região, pelo menos seis delas mantêm relações diretas e indiretas com a única escola que existe para atender o alunado presente nesse meio rural. A partir desse momento será mostrado como é estabelecida essa relação, onde buscou a reflexão sobre como a relação de produção implica nas questões inerentes ao ensino.

Cabe informar de antemão que a categoria PR-7, pelas condicionantes de não fixar moradia nessa zona rural, não tem ligação com a escola, pois são moradores de outras regiões e a relação que eles estabelecem com o espaço estudado é basicamente econômica.

Tendo em vista as relações expostas nos sete (7) quadros do item anterior, percebeu-se que a maioria das famílias que compõe o PR-1, PR-2 e PR-3 são trabalhadores que vendem, sobretudo, sua mão de obra manual entre os atores das mesmas categorias e para aquelas categorias mais abastadas. Esse processo foi representado no fluxograma (1): 
Fluxograma 1- Organização da oferta de trabalho manual no espaço rural estudado.

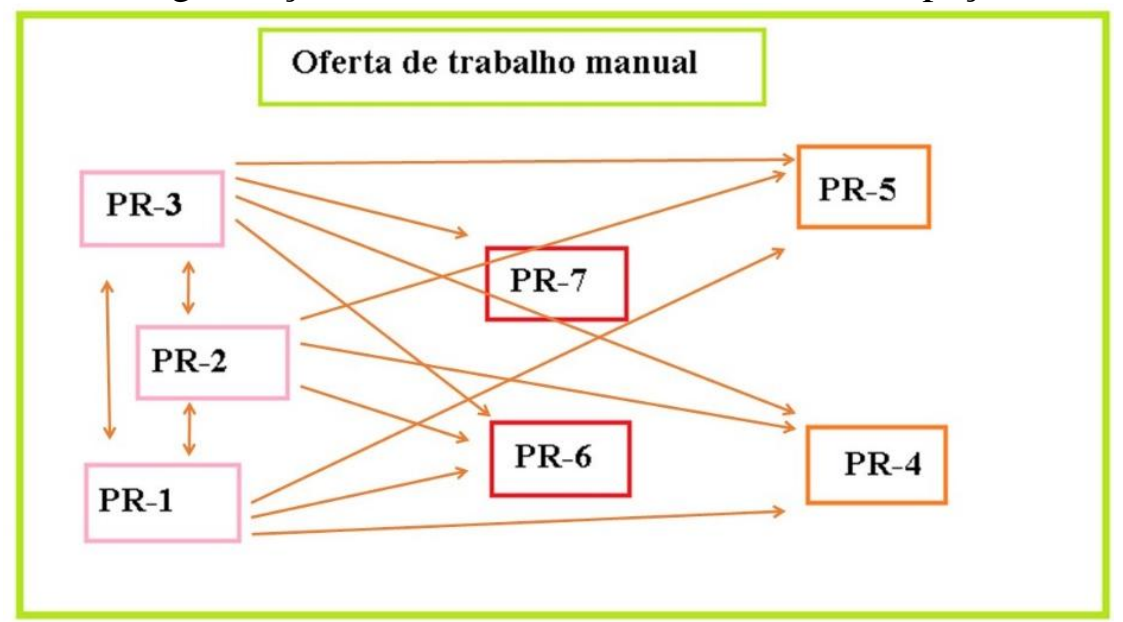

Fonte: Trabalho de Campo (2016).

As flechas abóboras indicam a oferta de mão de obra manual. O trabalho manual aqui mencionado trata-se por exemplo de: construção de cercas, cuidados com animais, carpina, colheita manual de grãos (milho, feijão e arroz), entre outras atividades que não demandam o uso de tecnologias mais complexas. Como indicado no fluxograma, são os PR-1, PR-2 e o PR-3 que mais oferecem esse tipo de serviço, tanto em forma de troca de dia de trabalho entre outros produtores, dessa mesma categoria, quanto para recebimento do dia trabalhado (em 2016, correspondia a $\mathrm{R} \$ 60,00 /$ dia).

As pessoas da categoria PR-1 são avós, tios, primos ou mesmo conhecidos de alunos e professoras que participam da escola. Caso essas pessoas não sejam responsáveis legais por algum dos alunos, eles não são envolvidos diretamente com a dinâmica escolar.

As crianças e os jovens das categorias PR-2, PR-3, PR-4 e PR-5 são em sua maioria alunos da escola, possuindo alguns aspectos que os diferenciam entre si, sobretudo, em relação as condições financeiras e de tempo para realização dos seus estudos. Muitos dos jovens, sobretudo das categorias PR-2 e PR-3, desenvolvem alguma atividade para ajudar e complementar a renda nos sítios dos pais, ou mesmo são empregados nas fazendas da região, tendo assim que conciliar estudo e trabalho.

Ora pelas condições financeiras, ora pela baixa autoestima, por se considerarem com baixa intelectualidade, grande parte desse alunado não almeja continuar os estudos e até mesmo desconhecem os processos de ingresso nas universidades públicas e privadas. 
Até o ano de 2009, esses alunos terminavam o Ensino Fundamental II, que até então era o nível de ensino obrigatório e buscavam se inserir no mercado de trabalho em outras cidades ou mesmo na zona rural. Depois que o ensino médio também passou a ser etapa obrigatória, embora exista ainda uma forte evasão, os pais e mães insistem para que eles terminem essa etapa de ensino, demostrando que os pais se envolvem e se interessam pelo ensino dos filhos e filhas.

Fluxograma 2- Organização do trabalho especializado no espaço rural estudado.

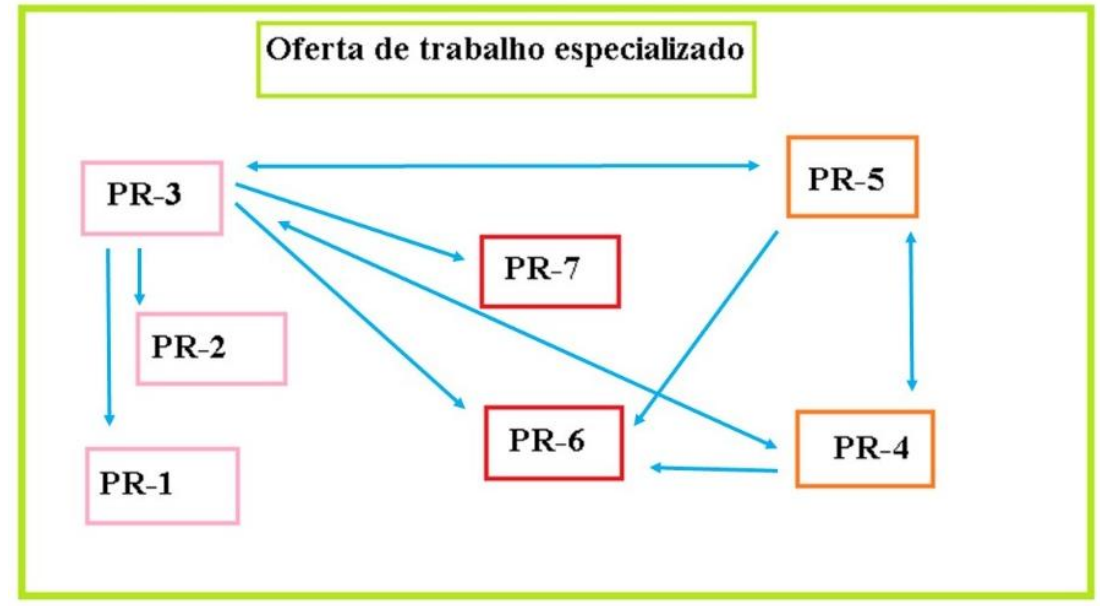

Fonte: Trabalho de Campo (2016).

No fluxograma (2), as flechas azuis indicam os fluxos de oferta de trabalho especializado. Nessa pesquisa, assume-se o termo trabalho especializado no sentido do trabalho que demanda conhecimentos técnicos sobre o uso de tecnologias específicas, desde tratores com roçadeiras, trinchas, adubadoras e colheitadeiras até aquelas máquinas agrícolas de grande porte com acesso a GPS. Os Produtores Rurais (PR-3) também oferecem além do trabalho manual, o trabalho especializado, sobretudo com tratores de pequeno porte, cabe ressaltar que essa oferta é em menor escala dos que os produtores rurais 4 e 5 (PR-4 e PR-5).

Os adolescentes que compõe as categorias PR-4 e PR-5, os quais almejam ingresso em universidade, procuram informações por contra própria, ingressam em faculdades de ensino à distância (EAD) para continuar prestando serviços aos fazendeiros e para garantir sua permanência no espaço rural. Parte desses jovens se veem obrigados a desistirem dos cursos, por falta de incentivos, devido à sobrecarga de trabalhos nos períodos de safra alta e devido ao baixo acesso a uma rede de internet que 
possibilite o acesso às plataformas educacionais de forma eficaz para realização das atividades remotas.

Considera-se esse fato uma forma de violência contra esses jovens, pois, ao mesmo tempo em que não se assegura a inserção e a permanência deles ao sistema educacional, eles são condicionados a servirem com sua mão de obra às fazendas da região. Neste sentido, concorda-se com Arruda (2004 p.66), quando este traz que "a educação visa a domesticação dos trabalhadores para a servidão voluntária" e que é por isso que a educação burguesa "precisa ser funcionalista, utilitarista e unilateral".

Além da falta de incentivo e pela sobrecarga de trabalho, a falta de acesso a uma internet de qualidade prejudica o processo de ensino aprendizagem desses alunos, tornando o ensino desinteressante, dificultando a continuidade deles.

Em oposição aos processos ocorridos entre as categorias PR-2 até os PR-5, os filhos e filhas dos PR-6 estudam na escola até atingir certa idade e, depois disso, seguem para as cidades da região para estudar em colégios particulares, geralmente para realizar o ensino médio e ingressar no ensino superior.

Com maior poder aquisitivo, os PR-6 podem ser considerados uma elite nesse território. Eles também compuseram por bastante tempo uma elite intelectual nesse espaço, desenvolvendo papéis fundamentais na gestão e na docência da escola, portanto, influenciando através de seus discursos (comunicação e informação) a formação de seus alunos, que por sua vez são atores oriundos de categorias que oferecem mão de obra aos mesmos.

Fluxograma 3-. Relação entre poder e ensino na escola rural estudado.

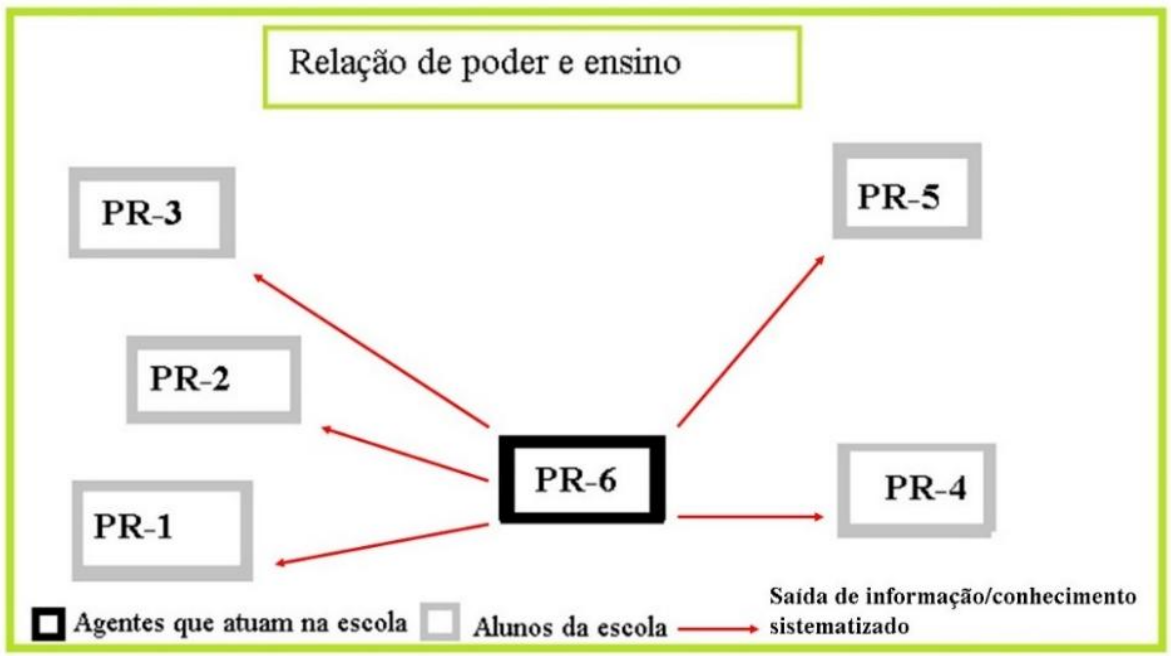

Fonte: Trabalho de Campo (2016). 
No fluxograma (3), as flechas vermelhas indicam de onde parte a saída de informações e de conhecimentos sistematizados. Nota-se que as direções das flechas vermelhas vão em direções opostas às direções das flechas azuis e abóboras (Fluxogramas 1 e 2). Isso indica de onde parte a oferta de trabalho no espaço estudado, mostrando que os maiores empregadores da região também são os responsáveis por educar esses alunos em questão.

Disso surgem questionamentos sobre como é o ensino oferecido por estes atores aos seus educandos: Sobre quais perspectivas eles desenvolvem seus métodos? Sobre quais ideologias? Seriam ideologias para libertação ou para manutenção da "ordem" e do sistema? Este ensino tem a intenção de formar quem? Formar para quê? Há espelhamento entre as relações externas (de trabalho) e as relações internas (de ensino) nestas relações?

Outra questão sobre o ensino nesse espaço que se torna relevante à reflexão é que a grade curricular, os conteúdos didáticos, dessa escola rural segue modelo urbano. O assunto agricultura familiar, por exemplo, somente aparece nos sétimos anos do Ensino Fundamental II nas aulas de Geografia de maneira conceitual, criando oposição básica ao agronegócio, mas sem grande aprofundamento do que significa isso na realidade dos alunos. (CRUZ; AZEVEDO, 2019).

Isso se agrava, tendo intencionalidade ou não, pela utilização dos livros didáticos sem que haja uma reflexão acerca do conteúdo contido neste material de apoio, pela prática indiscriminada de cópias do conteúdo (sem reflexão) e como atividades para os alunos. Neste sentido, ainda sobre os livros didáticos de Geografia do Ensino Médio, Silva e Oliveira (2013) trouxeram que o discurso dos livros didáticos em se tratando das questões agrárias tendem a sobrepor o agronegócio a agricultura familiar, negando sobretudo a importância da mesma.

Essa é uma realidade mostrada sobre o ponto de vista ideológico dominante, que não condiz com a realidade vivida dos alunos, ao contrário, reforça a distância entre o que é ensinado e vivido, muitas vezes ocultando e mistificando a realidade. Desse modo segundo Silva e Oliveira (2013, p.93) o livro pode ser utilizado como veículos da ideologia dominante na "Escola, a qual é por excelência um aparelho ideológico do Estado". 
Depois de visto tamanha diversidade existente no espaço estudado, considera-se de grande relevância um maior aprofundamento sobre esse modo de produção e de reprodução do meio rural, para compreensão de que esse espaço é sim um espaço dinâmico, onde acontecem diversas relações e delas surgem pontos de tensionamentos, e contradições, e de manutenção cultural, econômica e social.

\section{Considerações Finais}

Embora o espaço rural estudado seja um espaço consideravelmente pequeno, foi possível observar uma ampla gama de relações, sejam essas relações de ordem social, econômica, cultural e educacional. É necessário compreender que essas relações acontecem ao mesmo tempo, tornando o rural um espaço dinâmico. E levar essa dinâmica a ser pensada dentro das salas de aula é essencial para que os alunos se percebam como sujeitos ativos desse espaço.

Notou-se que, embora os atores rurais que compõem as categorias PR-1, PR-2, PR-3, PR-4 e PR-5 sejam maioria em quantidade na área estudada, o poder de influência, comunicação e empregabilidade dos PR-6 e PR-7 é o que determina as centralidades dos fluxos em Barranco Alto.

Desse modo, as relações existentes dentro do modo de produção, quando não são percebidas de forma crítica, podem também ser reproduzidas dentro do ambiente escolar, reforçando estereótipos e até mesmo a submissão contínua dos diferentes sujeitos do campo frente ao sistema.

Ensinar e aprender, partindo do que se vive e daquilo que se conhece, sem restringir as outras realidades, é essencial para que se formem cidadãos críticos, dispostos a resistir às mudanças que são impostas de cima para baixo, e que são negativas à sua formação, para se adaptar de forma consciente às mudanças que lhes podem agregar sentido à vivência.

Defende-se, então, a construção de uma educação do campo que atenda às necessidades dos sujeitos da agricultura familiar, que questione as formas de dominação e de exploração, que reconheça e fortaleça os anseios desses moradores, ou mesmo, que os agentes que componham o seio escolar desenvolvam consciência, senso crítico e criem ferramentas para que "ser" ou "estar" no espaço rural não seja uma consequência 
de não ter outras oportunidades e que o viver com dignidade, no campo, seja de fato um direito. Neste sentido, é relevante repensar a função da escola, é necessário a construção de uma escola que passe a existir em função da sua comunidade não ao contrário disso.

\section{REFERÊNCIAS}

ALVES Flamarion Dutra; VALE Ana Rute do. A relação campo-cidade e suas leituras no espaço. ACTA Geográfica, Boa Vista, Ed. Esp. Geografia Agrária, p.33-41. 2013.

ALVES Flamarion Dutra; LINDNER Michele. Agronegócio do café no sul de Minas Gerais: Territorialização, mundialização e contradições. Revista OKARA: Geografia em debate, v. 14, n. 2, p. 433-451. 2020.

ARRUDA, Marcos. A articulação trabalho-educação visando uma democracia integral. In: GOMEZ, Carlos Minayo (et.al.) Trabalho e conhecimento; Dilemas na educação do trabalhador. 5 ed. São Paulo, Cortez, 2004.

BRASIL, Reforma Agrária. LEI No 8.629, de 25 de fevereiro de 1993. https:// http://www.planalto.gov.br/ccivil_03/leis/18629.htm,. Acesso 31/01/2022.

BRASIL, Ministério da Educação. (2015). Guia dos Livros didáticos PNDL Campo (2016): Anos Iniciais do Ensino Fundamental. Ministério da Educação. Brasília: MEC.

BAGLI, Priscila. Rural e urbano: Harmonia e conflitos na cadência da contradição. In: SPÓSITO, Maria Encarnação Beltrão\& WHITACKER, Arthur Magon (orgs). Cidade e Campo: Relações e contradições entre urbano e rural. São Paulo: Expressão Popular, p.81-109, 2006.

CAMACHO, Rodrigo Simão. A relação dos movimentos socioterritoriais camponeses com a Universidade por meio do PRONERA: diálogos e tensionamentos. Revista NERA, p. 186-210, 2017.

CARLOS, Ana Fani Alessandri. Da "organização" à "produção" do espaço no movimento do pensamento geográfico. In. A PRODUÇÃO do espaço urbano: agentes e processos, escalas e desafios. São Paulo: Contexto, 2011.

CARNEIRO, M. J. Ruralidade: novas identidades em construção. Estudos Sociedade e Agricultura, 11, out., 1998: 53-75.

CRUZ, Abigail Bruna da; AZEVEDO, Sandra de Castro de. Geografia escolar e escola no campo: investigações sobre a educação geográfica numa escola rural com currículo urbano. Revista NERA, v. 22, n. 46, p. 133-155, jan.-abr. 2019.

LEFEBVRE, Henri. A produção do espaço. Trad. Doralice Barros Pereira e Sérgio Martins (do original: La production de l'espace. 4e éd. Paris: Éditions Anthropos, 2000). Primeira versão: início - fev.2006. 
MARTINS, Marcos Lobato. Olhares sobre o "Mar de Minas": percepções dos moradores de Alfenas e Fama relativas ao lago de Furnas (1963-1999). Ambiente \& Sociedade, Campinas v. XIII, n. 2, p. 347-363, jul.-dez. 2010.

MOREIRA, Ruy. Pensar e ser em geografia: Ensaios de história, epistemologia e ontologia do espaço geográfico. São Paulo, Contexto, 2015.

SCHNEIDER, Sérgio. Evolução e Características da Agricultura Familiar no Brasil. REVISTA ALASRU Análisis Latinoamericano del Medio Rural Nueva Época no.9, octubre, 2014.

SILVA, Joseli Maria; Dos Espaços interditos a instituição dos territórios travestis: Uma contribuição as geografias feministas e queer. In: Entre Geografias. Terra Livre. São Paulo SP Ano 26, V.2, n.35 p.53-72 Jul-Dez.2010.

SILVA, Maria Aline; Alexandra Maria de. Dialogando com o livro didático de Geografia: análise do discurso sobre a questão agrária em obras do ensino médio. Revista Ensino e Geografia.vol.17, n.3 set/ago. 2013.

VIERA, Noemia Ramos. O Conhecimento Geográfico Veiculado pelos Parâmetros Curriculares Nacionais de Geografia e o Espaço Agrário Brasileiro: Reflexões para uma Geografia Crítica em Sala de Aula REVISTA NERA - ano 7, n. 4 - jan/jul. 2004.

WANDERLEY, Mariade Nazareth Baudel. Agricutura familiar e campesinato: rupturas e continuidade. Estudos Sociedade e Agricultura. Rio de Janeiro, 2003. 